\title{
A Practical and Rapid Method of Histological Processing for Examination of Coronary Arteries Containing Metallic Stents
}

\author{
Heleen M. M. van Beusekom, MD, PhD, Deirdre M. Whelan, BSc, Monique van de Plas, MD, \\ and Willem J. van der Giessen, PhD
}

From the Department of Cardiology, Thoraxcenter, Erasmus University Rotterdam, The Netherlands

\begin{abstract}
$++$
A practical and rapid method was developed to study vascular pathology after implantation of metal endoprostheses (stents) that are used as internal splinting devices of tube-like structures. This method obviates the need for time-consuming grinding of thick sawing sections or removal of the prosthesis prior to histological processing, allowing for detailed analysis of the tissue in general, but especially of the stent-tissue interface. The vessels, with the metal stents still in place, were dehydrated in graded series of ethanol and embedded in methyl methacrylate. Using a motor-driven rotary microtome, 3- to 5- $\mu \mathrm{m}$ sections were easily cut. After deplastination, routine and special histological stainings were performed according to standard protocols for paraffin sections. This method proved to save time, compared with sawing sections, while allowing for a more complete examination of the stenttissue interface than is possible with routine paraffin techniques. Cardiovase Pathol 1996;5:69-76
\end{abstract}

Stents as endoluminal splinting devices are increasingly used as an alternative to surgery by providing inner mechanical support for internally stenosed or externally compressed hollow structures, such as the esophagus, trachea, bile ducts, ureters, veins, aorta, and peripheral and coronary arteries. As many of these applications are still in the investigational phase, histopathological examination is an important technique in the evaluation of the short- and long-term merits of this new treatment.

Standard preparatory techniques for evaluation of stented blood vessels, or any other tissue with metal implants, have their limitations, especially when they require the time-consuming removal of the prosthesis prior to embedding. When studying metallic endovascular prostheses (stents), as with any biomaterial implant, it is important to study not only the general tissue reaction, but also the interface between the receiv-

This study was supported by Grant No. 93-158 of the Netherlands Heart Foundation and the Interuniversity Cardiology Institute of The Netherlands (Project 18).

Manuscript received April 5, 1995; accepted July 18, 1995.

Address for reprints: Heleen M. M. van Beusekom, PhD, Department of Cardiology, Thoraxcenter, Ee 2357, Erasmus University Rotterdam, P.O. Box 1738, 3000 DR Rotterdam, The Netherlands. ing tissue and the implant surface. Removal of the prosthesis prior to embedding will often result in the loss of the direct stent-tissue interface and cause excessive damage to the tissue in case of complicated designs of the prosthesis (1). In studies of acute reactions to vascular implants this is especially true, as the usually limited amount of adherent cells is often lost. Current methods of histological preparation of implanted biomaterials in hard plastics enable the prostheses to be left in place but warrant the time-consuming preparation of thick sawing sections, sometimes followed by grinding to prepare thinner sections $(2,3)$. Although several techniques are available to stain these sections (4), the quality of the thick as well as the ground sections is not comparable to that of stained paraffin sections. Glycol methacrylate has also been described as an embedding medium for stented arteries (5), but it may not always he hard enough to allow cutting of the vessels while leaving the metal prosthesis in place, and it does not allow for a complete range of stainings to be performed.

This article describes a technique that obviates the need to remove the prosthesis prior to embedding, leaving the interface between the stent and the tissue intact. This is especially important for vascular tissue when studying the inter- 
action between blood and the vessel wall. The technique enables thin sectioning $(3-5 \mu \mathrm{m})$ while allowing for a whole range of routine and special stains to be carried out with a quality equal to that of paraffin sections and better than that of sawing sections.

\section{Materials and Methods}

Vascular implants. Stents of various designs and materials, such as the tantalum Wiktor stent (Medtronic Inc., Minneapolis, $\mathrm{MN}$ ), the stainless steel Wallstent (Schneider [Europe] AG, Buelach, Switzerland), Palmaz-Schatz stent (Johnson and Johnson Interventional Systems, Warren, PA), polymer stents (9), and polymer-coated metal stents (10) (Figure 1), were implanted in coronary arteries of pigs as previously described $(6,7)$. The pigs were sacrificed at intervals ranging from several hours to months following stent implantation.

Fixation and tissue retrieval. To retrieve the stented arteries, the thorax was opened by a midsternal split, and a lethal dose of sodium pentobarbital was injected intravenously. Thereafter, the ascending aorta was cross-clamped and the aortic root punctured above the coronary ostia for in situ pressure fixation (approximately $150 \mathrm{~cm} \mathrm{H}_{2} \mathrm{O}$ ) with $4 \%$ phosphate-buffered paraformaldehyde. Thereafter the coronary arteries were dissected free from the epicardial surface, and the tissue was kept in fixative for at least another 24 hours before methyl methacrylate embedding.

Embedding procedures. The stented coronary arterics with some surrounding tissue were dehydrated in a graded series of ethanol, impregnated in three changes of methy! methacrylate (MMA; E. Merck Nederland B. V., The Netherlands) as described in Table 1 , and modified from the method of Buijs and Docterom (8). After completion of the MMA. impregnation, the specimens were placed in glass vials; then $5 \mathrm{mg} / \mathrm{mL}$ perkadox 16 (bis [4-tert-butylcyclohexyl] perox. ydicarbonate; AKZO Nobel Chemicals, The Netherlands) was added to the MMA as a catalyst for polymerization and mixed well, and the specimens were oriented in the vial as required Plasticizers were not added. After a one-hour vacuum im pregnation to remove any air, the glass vials were carefully closed, and the MMA polymerized overnight in a $37 \% \mathrm{Cowen}$ As polymerization is an exothermous reaction, the vals con taining the specimen were kept in a container with water $t:$ prevent overheating. After completion of the polymerization process, the glass vials were broken and the polymerizeo blocks washed in water.

Sectioning and staining. After the excess MMA wa: trimmed off, sections were cut on a motor-driven rotary micretome (HM350, Microm GmbH, Munich, Germany) using stainless steel disposable knives (Superlap, Adanas In-
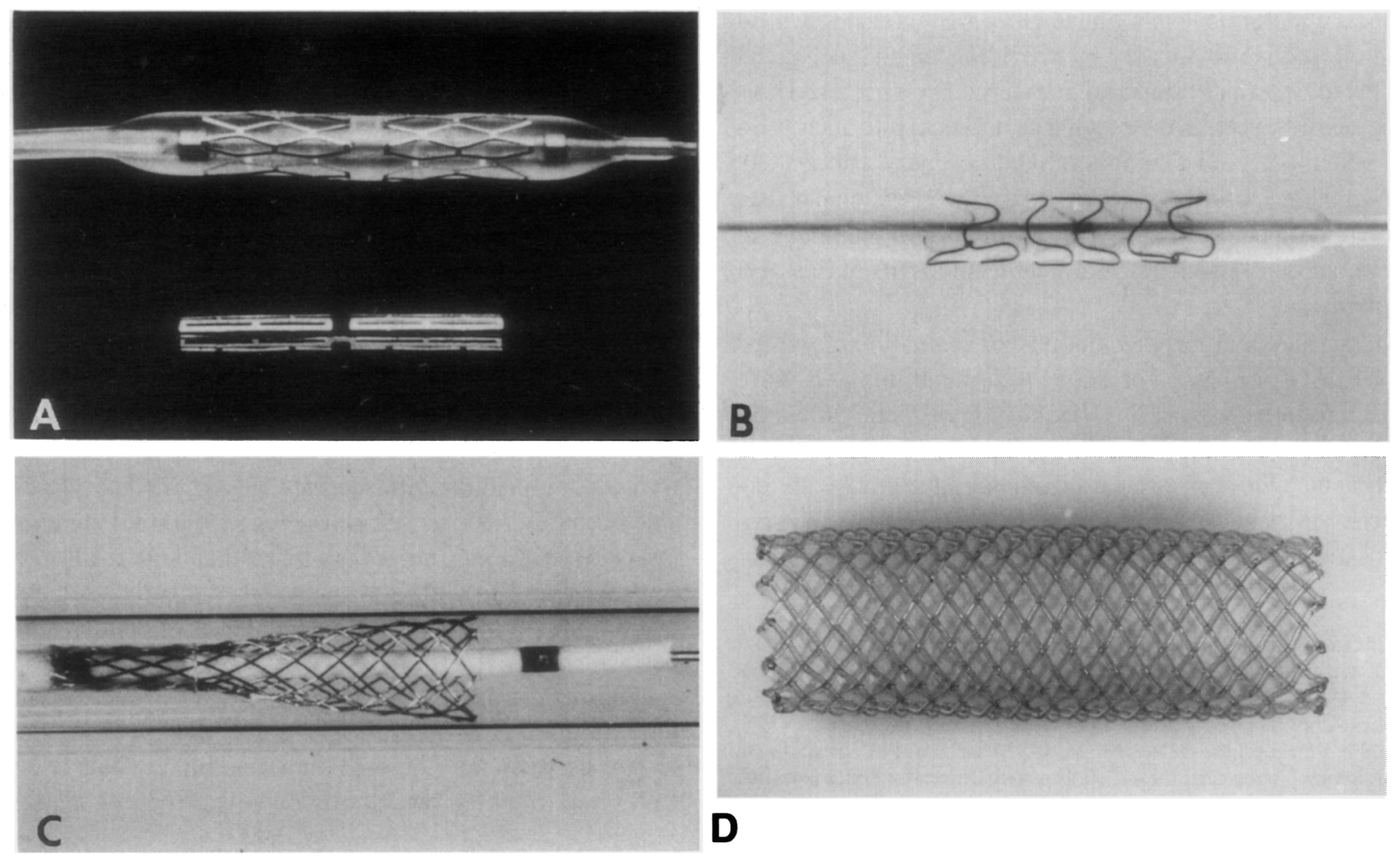

Figure 1. Various types of stents. (A) Palmaz-Schatz stent: (B) Wiktor stent; (C) Wallstent; (D) polymer stent. 
Table 1. Schedule for MMA Embedding

\begin{tabular}{|c|c|c|}
\hline $2 \times$ & $80 \%$ ethanol & $\mathrm{l} \mathrm{h}$ \\
\hline $2 \times$ & $96 \%$ ethanol & $1 \mathrm{~h}$ \\
\hline $2 \times$ & $100 \%$ ethanol & $1 \mathrm{~h}$ \\
\hline $1 \times$ & $100 \%$ ethanol & $10 \mathrm{~h}$ \\
\hline $2 x$ & $100 \% \mathrm{MMA}$ & I h \\
\hline $1 \times$ & $100 \%$ MMA & $5 \mathrm{~h}$ \\
\hline \multicolumn{3}{|c|}{ Add $5 \mathrm{mg} / \mathrm{mL}$ of perkadox to the MMA, mix } \\
\hline \multicolumn{2}{|c|}{ Vacuum impregnation } & l h \\
\hline \multicolumn{2}{|c|}{ Oven $\left(37^{\circ} \mathrm{C}\right)$} & $\geqslant 16 \mathrm{~h}$ \\
\hline
\end{tabular}

strumenten BV, Lecrsum, The Netherlands). While kecping the block surface wet, sections 3 to $5 \mu \mathrm{m}$ thick were cut. On chrome alum coated slides, sections were stretched on a hot plate at $40^{\circ} \mathrm{C}$ using a mixture of $60 \%$ 2-butoxyethanol and $10 \%$ ethanol in distilled water. Sections were covered by a plastic film, excess butoxyethanol-ethanol mixture was removed, and the slides were left overnight to dry in a $40^{\circ} \mathrm{C}$ oven.

Sections were deplasticized in a solution of equal volumes of xylene-chloroform for at least 30 to 60 minutes. Thereafter, standard staining protocols for paraffin sections were carried out, such as Goldner's trichrome stain and resorcinfuchsin as an elastin stain.

\section{Results}

Sectioning and staining. Several different stent materials, such as stainless steel, tantalum, and metal in combination with polymeric material, could be cut without difficulty. The intact MMA-embedded vessels containing the stents were sectioned at several intervals along their lengths. For every tissue level to be studied, approximately 10 sections were cut per stain (to allow for difficulty with stretching and adhering of the sections). Additional dry sections from each level were stored in case further analysis was required. The thickness of the stent wires $(70-130 \mu \mathrm{m})$ did not pose any problem during sectioning, although the amount of scoring in the tissue sections varied among the different types of metal stents. The average time needed for trimming and sectioning of four tissue levels (i.e., 40 sections) with subsequent stretching and adhering to glass slides is approximately two hours.

Following deplastination, hematoxylin-eosin, resorcinfuchsin, and Goldner trichrome stainings were carried out according to standard protocols for paraffin sections. The results are illustrated in Figures 2 through 6.

Figures 2 and 3 illustrate paraffin embedding of stented vessels compared with MMA embedding. The intact neointima over the stent wires in Figure 3 is in stark contrast to that in Figure 2B. During sectioning the metal often scores the tissue, but the resulting damage is never such that it interferes with pathological assessment. As the sections are very thin, the metal may often dislodge from the section, leaving a void (Figure 4). However, small amounts of adherent cells, thrombus, and proteinaceous material remain present for evaluation of the blood and tissue response to the implant (Figures 4 and 5). The complicated and intricate design of some stents (e.g., the polymer-coated stents shown in Figures 6A and 6B) means that removal of the stent wires would cause extensive damage to the vessel. Such removal would most certainly involve the removal also of the polymer, with subsequent loss of the delicate interface between the polymer and tissue and the metal and tissue. Such interfaces are well preserved with an MMA embedding technique, while damage to the vesscl causcd by the operator is kept to a minimum. The cellular detail of the inflammatory response to the polymer is clearly evident in Figure 6B.

Various types of stents and stent materials were all successfully embedded in MMA and sectioned to give clear and detailed results.

\section{Discussion}

Over the last few years there has been a dramatic increase in the use of percutaneous implants, both in patients and in the experimental setting. The desire to achieve the "perfect" implant device has led to the development of numerous stent designs, the short- and long-term effects of which must be assessed prior to patient use. Histology is one of the key techniques to assess these short- and long-term effects.

The behavior of a material as a vascular implant is dictated by the acute and chronic response to blood as well as the response of the vascular tissue to the foreign material. When studying the pathology of blood vessels containing metal or other endovascular prostheses, it is therefore important to study the interface between the prosthetic material and the surrounding tissue. This is especially true in studies of acute reactions to vascular implants, as the prosthesis is not incorporated in the vessel wall and the amount of adherent cells and proteins is often limited. Removal of the prosthesis prior to histological processing usually results in loss of the direct stent-tissue interface.

Implantation trauma can be another determinant for success or failure of an endovascular implant. As removal of the prosthesis often results in tears between the several tissue layers, this makes it difficult to assess whether the observed vascular damage is attributable to the implantation procedure or is a preparation artifact. This is a problem often encountered in the assessment of paraffin sections of stented vessels.

The procedures described in this paper obviate the need to remove the prosthesis prior to histological processing and allow for whole embedding of the arterial segments to be studied. The technique requires no special apparatus, as old automated paraffin tissue processors can easily be converted to MMA processing schedules. The microtome used in this study can also be adapted for paraffin sectioning. This therefore serves a dual function, reducing the need and the cost of having two separate instruments. The quality of the sections (3-5 $\mu \mathrm{m})$ in terms of the staining, morphology, and architecture of the tissue is equal to that of paraffin sections but is 

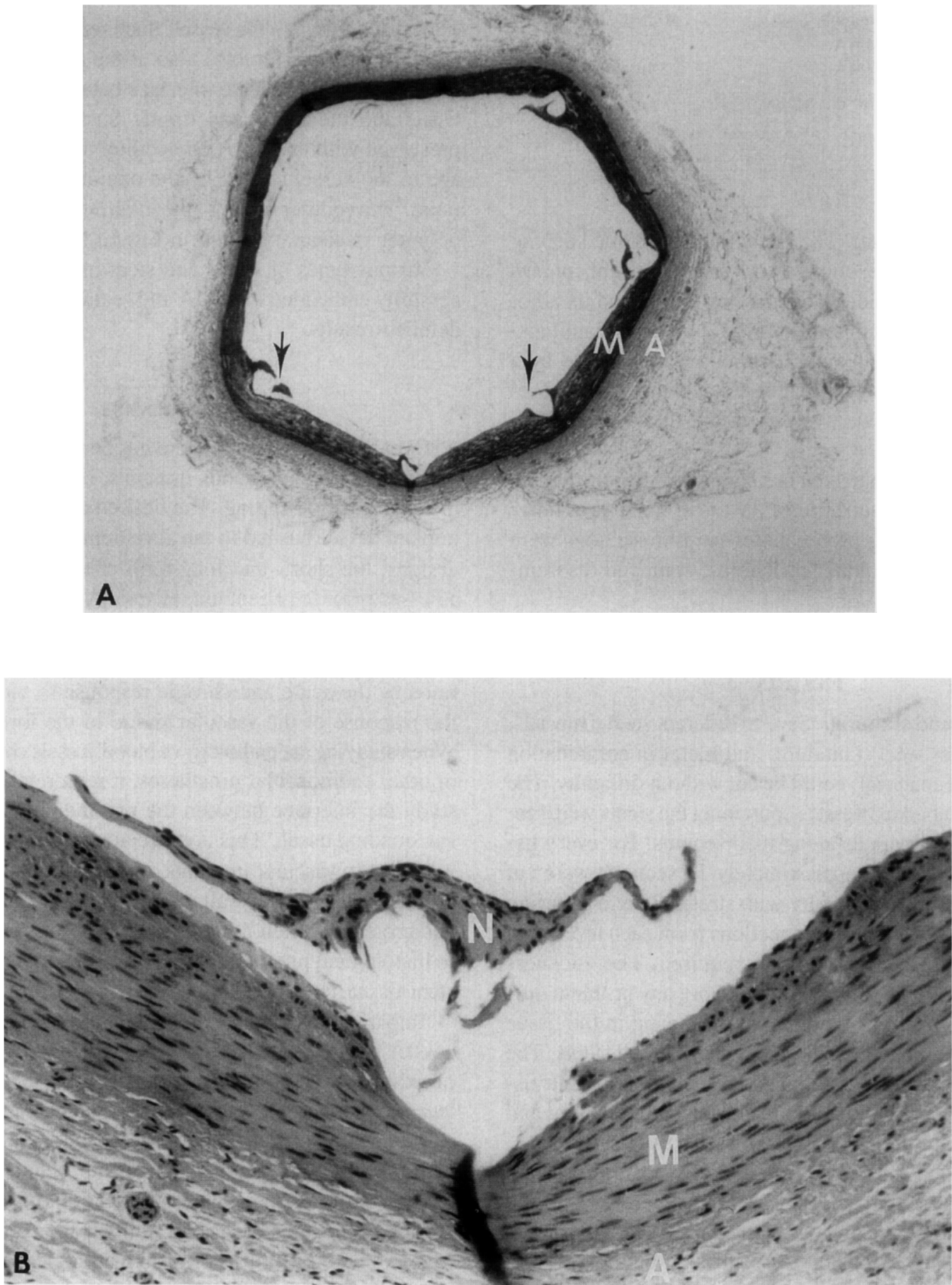

Figure 2. (A) View of a paraffin-embedded porcine coronary artery with the stent wires removed. Note the damage to the overlying neointima (arrows). $(\mathrm{M}=$ media; $\mathrm{A}=$ adventia. Goldner trichrome stain, original magnification $\times 19$.) (B) Detail of Figure $2 A$ illustrating tissue damage when the stent wire is removed. The overlying neointima $(\mathrm{N})$ is completely detached from the media $(\mathrm{M})$. (A : adventia. Hematoxylin-cosin stain, original magnification $\times 287$.) 


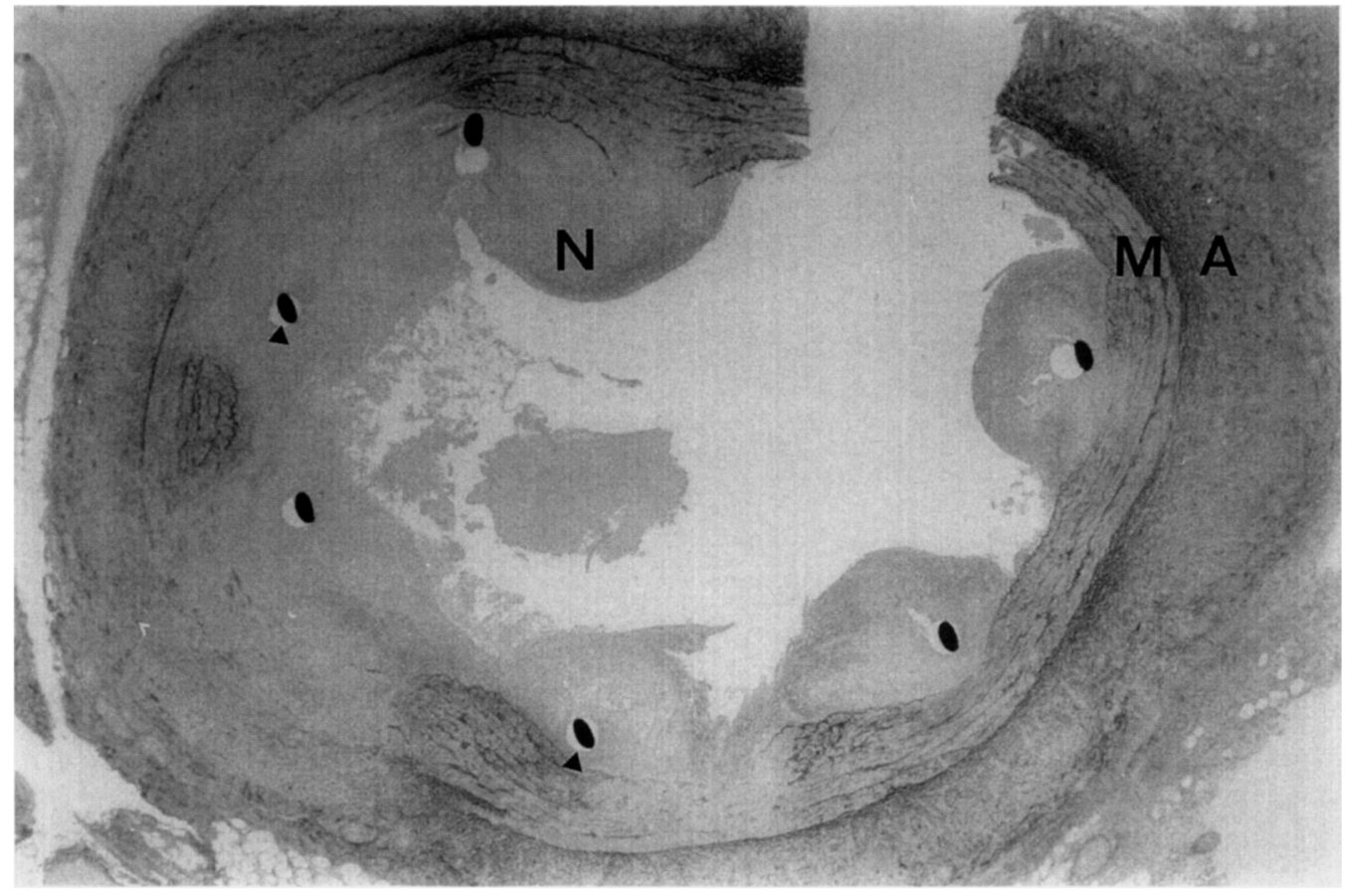

Figure 3. View of an MMA section of a plastic-embedded porcine coronary artery with the metal stent wires (arrowheads) in place and the overlying neointima $(\mathrm{N})$ still intact. $(\mathrm{M}=$ media; $\mathrm{A}=$ adventitia. Resorcinol-fuchsin stain, original magnification $\times 29$.)

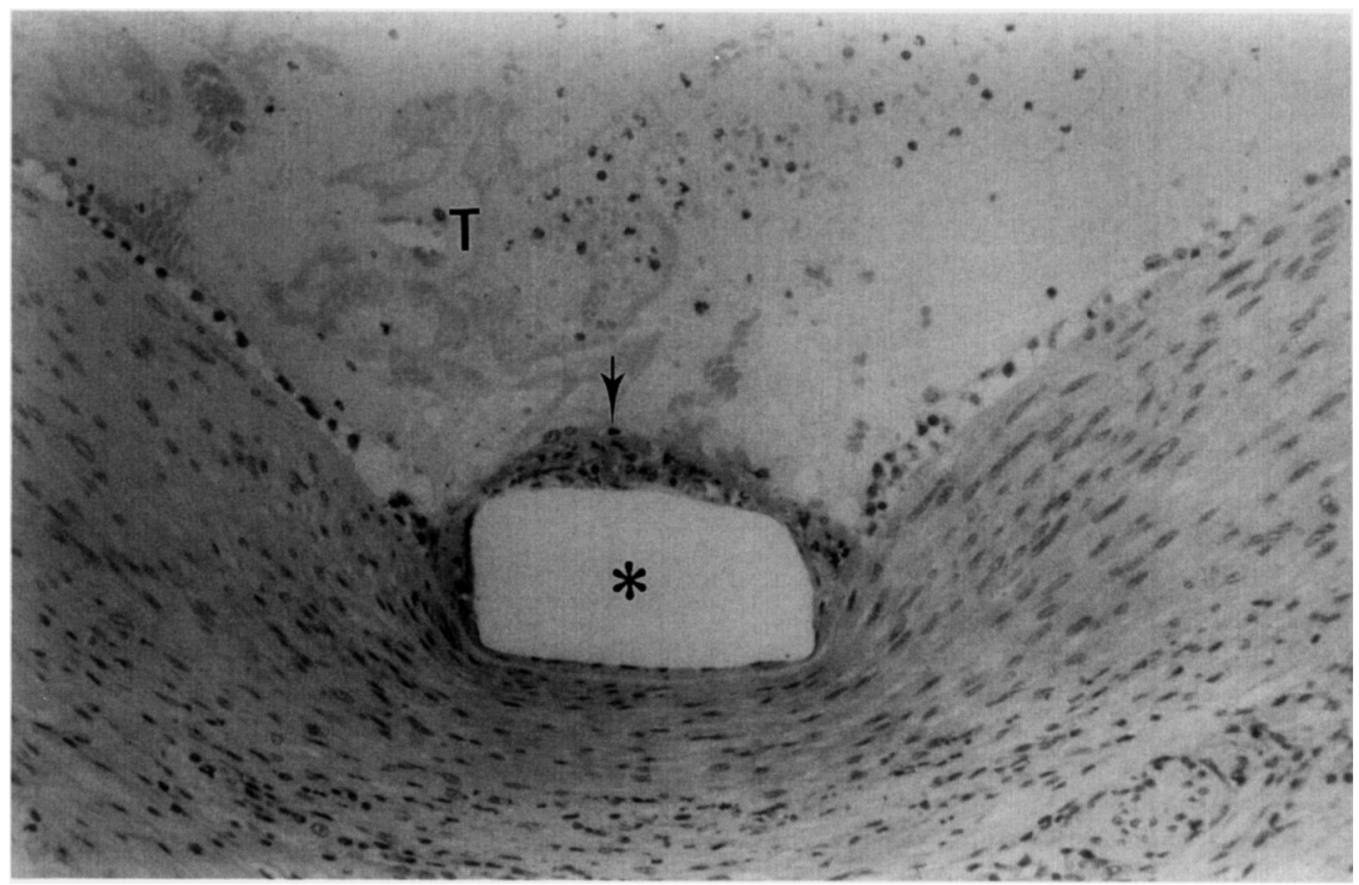

Figure 4. MMA section showing a stent wire void $(*)$ with overlying thrombus $(\mathrm{T})$ and adherent cells (arrow) still attached. Such detail is usually lost on removal of the wires prior to paraffin embedding. (Hematoxylin-eosin stain, original magnification $\times 579$.) 

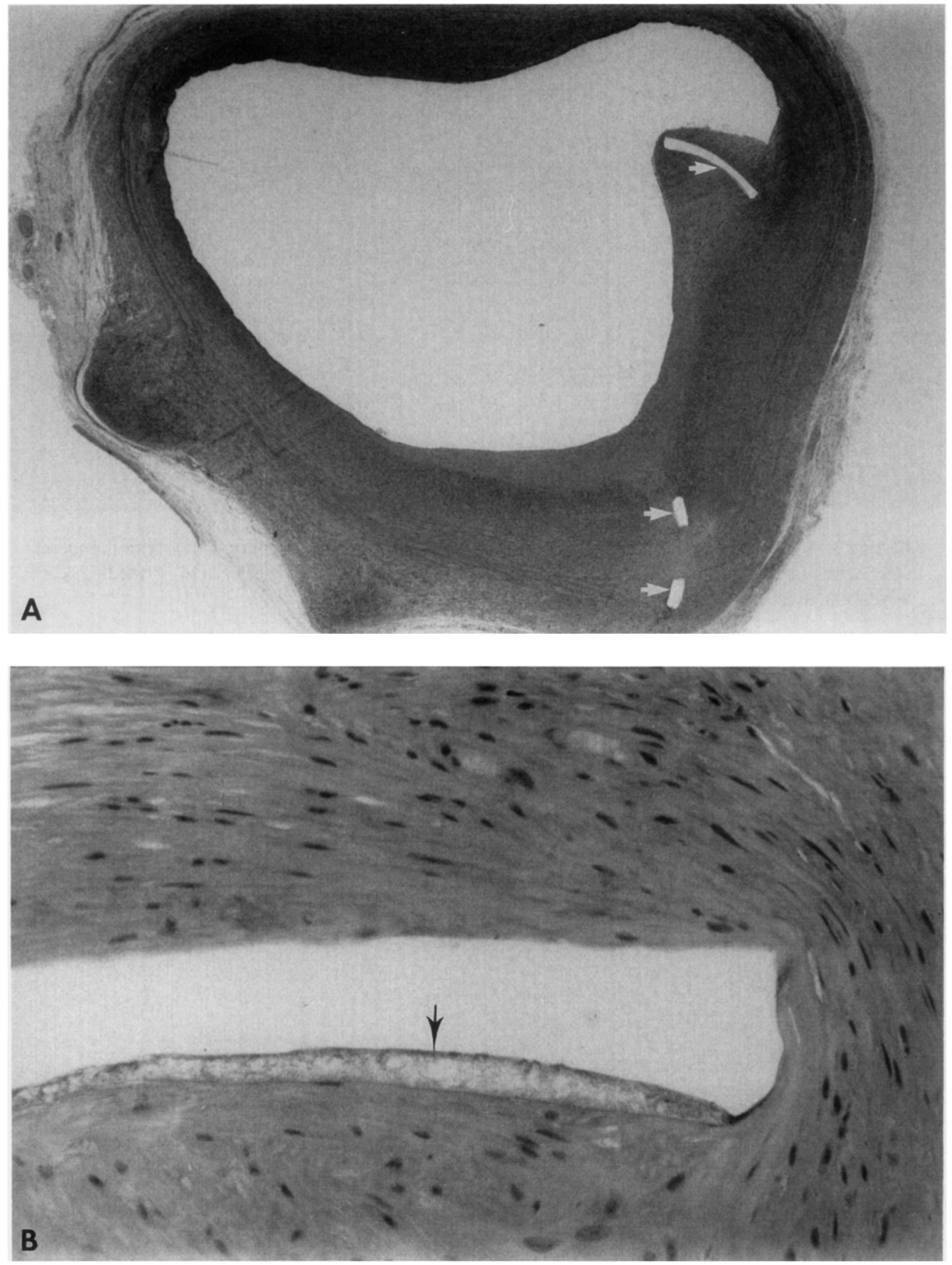

Figure 5. (A) View of an MMA section of a porcine coronary artery with a Palmaz-Schatz stent implant. Stent holes are indicated by the arrows. (Hematoxylin-eosin stain, original magnification $\times 29$.) (B) Detail of Figure 5A showing a stent hole with proteinaceous material (arrow) still present. (Hematoxylin-eosin stain, original magnification $\times 579$.) 

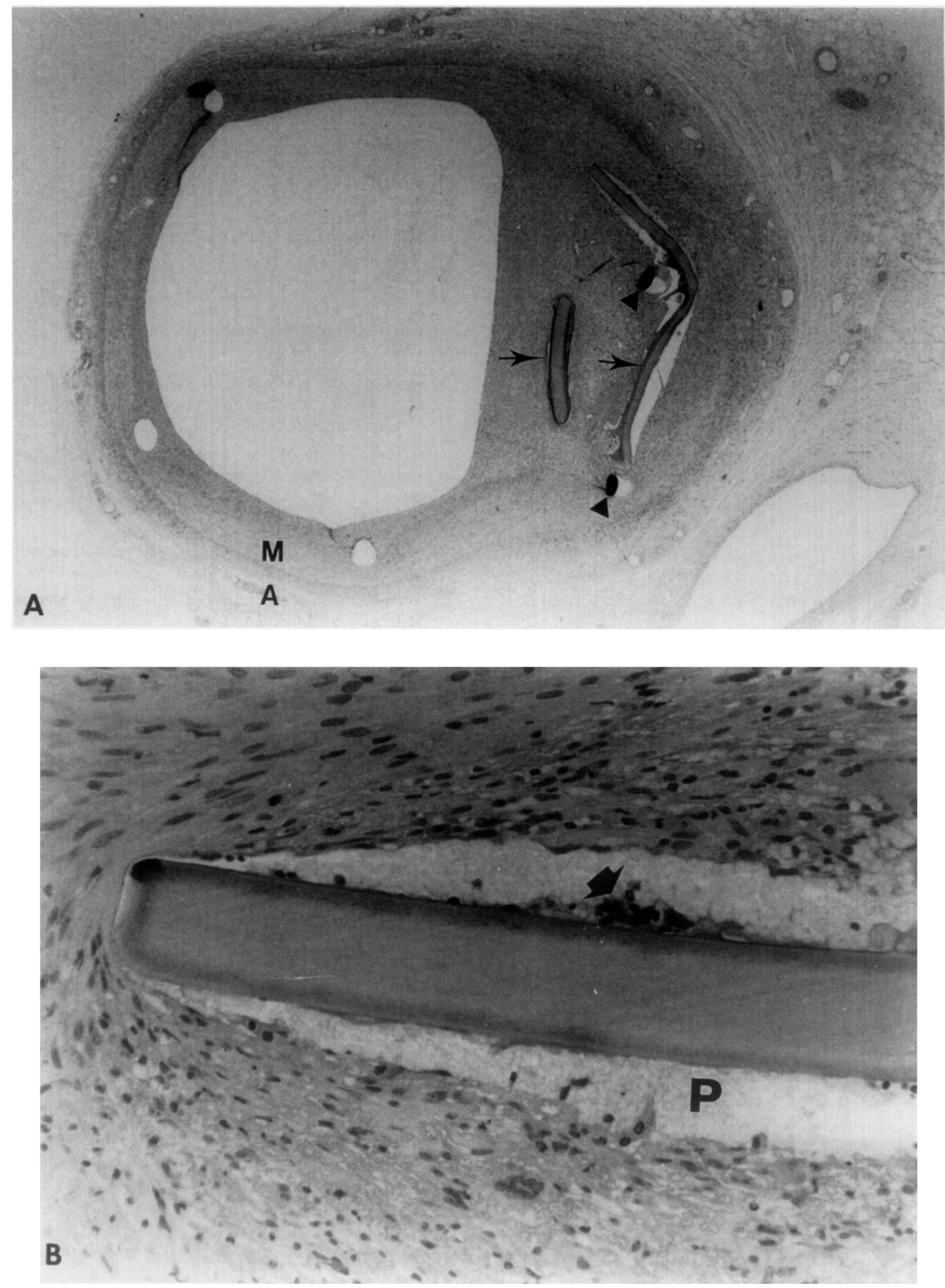

Figure 6. (A) MMA section of a porcine coronary artery with a polymer-coated Wiktor stent implant. The polymer coating (arrows) is clearly evident between the stent wires (arrowheads). ( $\mathrm{M}=$ media; $A=$ adventia. Hematoxylin-eosin stain, original magnification $\times 29$.) (B) Detail of polymer with adherent cells (arrow) and proteinaceous material (P) still attached. (Hematoxylin-eosin stain, original magnification $\times 287$.) 
better than that of sawing sections $(10 \mu \mathrm{m})$, for which only limited stainings are possible and magnification and resolution at higher power are not possible because of section thickness. The major advantage of this technique over paraffin techniques is that the prosthesis is not removed, allowing the delicate interface between the tissue and prosthesis to remain. It is considered to create less preparation artifact than paraffin processing and is less time consuming than sawing and grinding sections. Although the metal can score the sections to some extent, the resulting damage is never such that it interferes with pathological assessment.

\section{Conclusion}

The procedure described in this paper is a rapid and practical method for evaluating the histology of stented blood vessels, allowing a detailed analysis of the tissue reaction to vascular implants while leaving the prosthesis in place.

\footnotetext{
The authors wish to thank Pieter Derkx, Alex Nigg, and Ton de Jong of the Department of Pathology for their technical assistance and advice dur. ing the evaluation of this technique. We would also like to thank the following companies for their sponsorship: Schneider $\mathrm{AG}$, Johnson and Johnson Interventional Systems, and Medtronic Inc.
}

\section{References}

1. Van Beusekom HMM, Van der Glessen WJ. Van Suylen RA. BOW L. Bosman FT. Serruys PW. Histology after stenting of human saphenou: vein bypass grafts: observations from surgically exeised grafts 310.20 days after stent implantation. I Am Coll Cardiol 1993:21.45 54

2. Murice-Lambert E, Banford AB, Folger RL. Histological preparation? of implanted biomaterials for light microscopic evaluation of the implant tissue interaction. Stain Technol $1989 ; 64(1): 19-34$

3. Van der Lubbe HBM. Klein CPAT, de Groot $\mathrm{K}$, A simple methou hin preparing thin $(10 \mu \mathrm{m})$ histological sections of undecalcified plastic en bedded bone with implants. Stain Technol 1988,63(3):17117\%

4. Hahn M. Vogel M. Delling G. Undecalcified preparation of bune is sue: report of technical experience and development of new methods. Virchows Arch A Pathol Anat 1991;418:1-7.

5. Carter AJ. Laird JR. Farb A. Kuls W, Wortham DC Virman k. Mos phologic characteristics of lesion formation and time course of smooth muscle cell proliferation in a porcine proliferative restenosts model : Am Coll Cardiol 1994;24:1398 $\ldots 1405$

6. Van der Giessen WJ. Serruys PW, van Beusekom HMM. at ane nary stenting with a new, radiopaque, balloon-expandable endoprosthesis in pigs. Circulation 1991:83:1788-1798

7. Van der Giessen WJ, van Beusekom HMM, van Houten CD. van Woet kens LJ, Verdouw PD. Serruys PW. Coronary stenting with polymer coated and uncoated self-expanding endoprostheses in pigs. Coromary Artery Dis 1992:3:631-640.

8. Buijs R. Docterom AA. An improved method for embedding hard tis. sue in polymethyl methacrylate. Stain Technol $1983 ; 58(3) \div 135-140$

9. Van Beusekom HMM. Van der Giessen WJ, Wagenvoort ( A. Van ingert Schendu DS, Huijts RA, Serruys PW. Histological features of a polymer endovascular prosthesis after transcatheter implantation in porcine arteries. Cardiovase Pathol 1993; 2(1):41 52.

10. Lincoff AM, Schwartz RS, van der Giessen Wy, van Beusekom HMM, Serruys PW, Holmes DR, Ellis SG, Topol EJ. Biodegradable polymers can evoke a unique inflammatory response when implanted in the coronary artery. Circulation 1992; 86(4);1-801 (Abstr. 3186 ) 